\title{
PHYSICAL FITNESS LEVELS OF BULGARIAN PRIMARY SCHOOL CHILDREN IN RELATIONSHIP TO OVERWEIGHT AND OBESITY
}

\author{
Iveta Bonova, Stefan Kolimechkov, Oleg Hristov, \\ Borislava Petrova, Nadezhda Kostova \& Anna Vekova \\ National Sports Academy 'Vassil Levski', Sofia, Bulgaria
}

\begin{abstract}
The health-related physical fitness of children, alongside overweight and obesity rates, have been shown to be of great interest amongst physical education teachers, sports coaches, scientists, and health practitioners. Physical fitness is a major factor, which can predict the health status in the later phases of children lives. The aim of this study was to assess the health-related physical fitness levels in primary school children, in addition to providing estimates for overweight and obesity for children at this age. This study consisted of 118 primary school children (64 girls and 54 boys from Sofia, Bulgaria) between the ages of 7 and 11. The participants completed the Alpha-Fit health-related physical fitness test battery, which included anthropometric measurements and different tests (handgrip strength, standing long jump, $4 x 10 \mathrm{~m}$ shuttle run test, and $20 \mathrm{~m}$ multistage fitness test). The mean percentile scores of height, weight and BMI in all participants were within the WHO norms. However, the individual BMI assessment showed that $20.3 \%$ of all primary school children were 'overweight' (BMI > 85th percentile), $8.5 \%$ were 'obese' (BMI > 97th percentile), and $13.5 \%$ were assessed as 'thin' (BMI < 15th percentile). The results of this study showed that lower levels of physical fitness are associated with overweight and obesity in primary school children.
\end{abstract}

Key words: physical fitness, children, Alpha-Fit, overweight, obesity

\section{INTRODUCTION}

The health-related physical fitness in children has been shown to be of great importance for children's development, and has been widely discussed in the field of physical education and sport. Physical fitness is considered as a key factor in childhood (Ruiz et al., 2006, Ortega et al., 2008), and can be used to monitor and predict the health status of children (Ruiz et al., 2009). Measuring anthropometric parameters, as well as testing physical fitness components, is crucial in order to make a comprehensive assessment of the health-related physical fitness of children. A comprehensive review in many longitudinal studies concluded that a higher level of cardiorespiratory fitness, muscular strength and body composition is associated with a healthier cardiovascular profile and with a lower risk of developing cardiovascular diseases, and a healthier body composition in childhood is also associated with a lower risk of death in adulthood (Ruiz et al., 2009). Those health-related components are the core of the Alpha-fit test battery, which was designed to provide instruments for assessing physical fitness in a comparable way within the European Union (ALPHA, 2009). Based on a substantial number of studies, the Alpha-fit battery provides a full set of valid, reliable, feasible and safe field-based fitness tests to be applied for health monitoring purposes in children (Santos and Mota, 2011, ALPHA, 2009, Espana-Romero et al., 2010, Ruiz et al., 2010).

Interest in assessing and monitoring children's physical fitness has grown substantially over the last few decades due to a variety of health issues, such as overweight and obesity, as well as uncommon diseases for this age, for instance, diabetes and high blood pressure.

\section{Aim And Objectives Of The Study}

The aim of this cross-sectional study was to assess the health-related physical fitness levels in boys and girls between the ages of 7 and 11, in addition to providing estimates for overweight and obesity in a sample of primary school children from Sofia, Bulgaria. The realisation of this aim implies the following objectives: measurement and assessment of anthropometric parameters, testing and evaluating musculoskeletal fitness, motor fitness and cardiorespiratory fitness.

\section{METHODS}

This study consisted of 118 primary school children between the ages of 7 and 11, who were divided by 
their gender into two groups: 64 girls with a mean age of $9.1 \pm 1.0$ years, and 54 boys with a mean age of $9.1 \pm 1.0$, from Sofia, Bulgaria. In addition, the sample was also divided based on their BMI assessment (children with BMI percentile score (PRs) within the norms vs overweight or obese children), in order to investigate whether levels of physical fitness are associated with overweight and obesity in the primary school children. The study was carried out at the 'Hadji Dimitar' Primary School N42 and 'Nikolay Hrelkov' Primary School N53 during the spring of 2019. Informed consent for this research was obtained from the parents of each child prior to testing.

The participants of this study completed the Alpha-Fit health-related physical fitness test battery (ALPHA, 2009), which includes different anthropometric measurements (height, weight, waist circumference, triceps and subscapular skinfolds), as well as a variety of different fitness tests (handgrip strength, standing long jump, $4 \times 10 \mathrm{~m}$ shuttle run test, and $20 \mathrm{~m}$ multistage fitness test). The body mass index (BMI) with the percentile scores for height, weight and BMI for each child were calculated and evaluated by using the WHO AnthroPlus software (WHO, 2011). The percentile scores (PRs) were assessed by using the following classification: BMI > 85th PRs - 'overweight'; BMI > 97th PRs - 'obese'; BMI < 15th PRs - 'thin'; and BMI < 3rd PRs - 'severely thin' (WHO, 2007a). In addition, waist-to-height ratio (WHtR) was calculated (waist circumference $(\mathrm{cm}) /$ height $(\mathrm{cm}))$. Furthermore, upper arm muscle area (UAMA) was also calculated by using the following formula (UAMA $=[$ Arm circumference $-(\pi \mathrm{x}$ triceps skinfold $)] 2 \div 4 \mathrm{x} \pi$ ), and its percentile scores were computed based on recent norms for children (Addo et al., 2017).

The body fat percentage (\%Fat) was calculated as the sum of two skinfolds, using Slaughter's equations (Slaughter et al., 1988), and the body fat PRs were computed by using international norms for children (McCarthy et al., 2006).

Handgrip strength was measured by using the TKK digital hand dynamometer (TKK 5101 Grip-D, Japan) and the individual optimal grip span was calculated for each child prior to testing by using the equations for girls and boys between the ages of 6 and 12 (Espana-Romero et al., 2008). The standing long jump test was recorded to within an accuracy of $1 \mathrm{~cm}$, and the $4 \times 10 \mathrm{~m}$ shuttle run test was performed by using a stopwatch to an accuracy of 0.1 sec. Percentile scores for the handgrip strength, standing long jump and $4 \times 10 \mathrm{~m}$ shuttle run tests were calculated by using the full set of recently proposed values for the tests from the Alpha-Fit battery in European children (Kolimechkov et al., 2019). The software, specialised for children, this being BeepShuttle Junior (Kolimechkov et al., 2018, BeepShuttle Junior, 2017) was applied to administer the $20 \mathrm{~m}$ multistage fitness test with the original 1-minute protocol, as described by Leger et al. (Leger et al., 1984), and to calculate the estimated maximal oxygen uptake $\left(\mathrm{VO}_{2} \max \right)$. In order to assess the $\mathrm{VO}_{2} \max$ of the participants, BeepShuttle Junior also computed the percentile score for each individual based on age- and gender-specific international norms (Miguel-Etayo et al., 2014, Tomkinson et al., 2016).

The statistical analyses were conducted with SPSS Statistics 19, IBM, USA software, using descriptive statistics and the Kolmogorov-Smirnov test of normality. The parameters which showed a normal distribution were compared by using the independent t-test, and those with an abnormal distribution by applying the non-parametric Mann-Whitney U test. Statistically significant differences between the mean values were evaluated at $\mathrm{p}<0.05$, and all data in the manuscript are presented as mean \pm SD. Percentile scores (PRs) were compared to the $50^{\text {th }}$ percentile of the norms for primary school children by using one sample t-test in order to support the results analyses.

\section{RESULTS}

The anthropometric parameters, with their corresponding percentile scores (PRs) of the primary school children, are presented in Table 1 . There was no significant difference between the anthropometric parameters of the children of both genders. The mean PRs of height, weight, and BMI in the primary school children were within the normal WHO international norms $\left(>15^{\text {th }}\right.$ PRs and $<85^{\text {th }}$ PRs). Similarly, the mean PRs of \%Fat were also within the healthy norms. The mean BMI PRs for girls did not differ significantly from the $50^{\text {th }}$ percentile (56.4 PRs, $p>0.05$ ), and the BMI PRs for boys was slightly higher than the $50^{\text {th }}$ percentile of the WHO norms for BMI (59.8 PRs, $\mathrm{p}<0.05)$. The mean upper arm muscle area (UAMA) PRs for the girls and boys did not differ significantly from the $50^{\text {th }}$ percentile of the children's norms (Table 1 ). 
Table 1. Anthropometric parameters, with their corresponding percentile scores, of the primary school children divided by their gender (mean $\pm S D$ ).

\begin{tabular}{|l|c|c|c|}
\hline & Girls $(\mathrm{n}=64)$ & Boys $(\mathrm{n}=54)$ & $\mathbf{p}$ \\
\hline Age (years) & $\mathbf{9 . 0 9} \pm 1.02$ & $\mathbf{9 . 1 4} \pm 1.01$ & $\mathrm{p}>0.05^{*}$ \\
\hline Height $(\mathbf{c m})$ & $\mathbf{1 3 6 . 7 7} \pm 10.51$ & $\mathbf{1 3 7 . 9 8} \pm 9.98$ & $\mathrm{p}>0.05^{\mathrm{x}}$ \\
\hline Height - percentile score & $\mathbf{6 1 . 7 2} \pm 27.97$ & $\mathbf{6 8 . 3 9} \pm 25.36$ & $\mathrm{p}>0.05^{\mathrm{x}}$ \\
\hline Weight (kg) & $\mathbf{3 2 . 6 0} \pm 8.86$ & $\mathbf{3 2 . 7 5} \pm 6.94$ & $\mathrm{p}>0.05^{\mathrm{x}}$ \\
\hline Weight - percentile score & $\mathbf{5 9 . 0 6} \pm 30.82^{++}$ & $\mathbf{6 6 . 0 3} \pm 31.22^{++}$ & $\mathrm{p}>0.05^{\mathrm{x}}$ \\
\hline BMI (kg/cm $)$ & $\mathbf{1 7 . 1 9} \pm 2.78$ & $\mathbf{1 7 . 0 3} \pm 2.14$ & $\mathrm{p}>0.05^{\mathrm{x}}$ \\
\hline BMI - percentile score & $\mathbf{5 6 . 4 3} \pm 31.38$ & $\mathbf{5 9 . 8 4} \pm 30.24$ & $\mathrm{p}>0.05^{*}$ \\
\hline Arm circumference (cm) & $\mathbf{2 0 . 2 3} \pm 2.59$ & $\mathbf{2 0 . 2 7} \pm 2.77$ & $\mathrm{p}>0.05^{\mathrm{x}}$ \\
\hline Waist circumference (cm) & $\mathbf{5 8 . 5 4} \pm 7.36$ & $\mathbf{6 0 . 2 7} \pm 6.63$ & $\mathrm{p}>0.05^{\mathrm{x}}$ \\
\hline Waist-to-height ratio & $\mathbf{0 . 4 3} \pm 0.05$ & $\mathbf{0 . 4 4} \pm 0.04$ & $\mathrm{p}>0.05^{\mathrm{x}}$ \\
\hline \% Fat & $\mathbf{1 8 . 3 9} \pm 6.72$ & $\mathbf{1 6 . 7 2} \pm 7.19$ & $\mathrm{p}>0.05^{\mathrm{x}}$ \\
\hline \% Fat - percentile score & $\mathbf{2 9 . 3 5} \pm 36.66$ & $\mathbf{3 5 . 7 4} \pm 35.48$ & $\mathrm{p}>0.05^{\mathrm{x}}$ \\
\hline UAMA $\left(\mathbf{c m}^{2}\right)$ & $\mathbf{2 1 . 4 2} \pm 4.57$ & $\mathbf{2 2 . 6 3} \pm 5.07$ & $\mathrm{p}>0.05^{\mathrm{x}}$ \\
\hline UAMA - percentile score & $\mathbf{5 0 . 5 3} \pm 25.48$ & $\mathbf{4 8 . 9 5} \pm 34.12$ & $\mathrm{p}>0.05^{\mathrm{x}}$ \\
\hline
\end{tabular}

${ }^{+}$WHO does not provide weight-for-age reference data for children older than 10 years of age (WHO, 2007b).

${ }^{++} n=52$ for girls and $n=42$ for boys, because 24 of the children were older than 10 (see ${ }^{+}$).

* - compared by using the $t$-test for independent samples

$x$ - compared by using the Mann-Whitney $U$ test for independent samples

The individual PRs of BMI in the girls showed that PRs).

9 of the 64 females were assessed as 'overweight', The results from the Alpha-Fit health-related phyand 8 as 'obese'. Additionally, 15 of the 54 boys were sical fitness tests, in addition to the corresponding assessed as 'overweight' and 2 as 'obese'. On the PRs of the primary school children, divided accorwhole, the individual BMI assessment showed that ding to gender, are presented in Table 2.

$20.3 \%$ ( 24 children) of all primary school children Table 2. Results from the Alpha-Fit health-related were 'overweight' (BMI > 85th PRs), $8.5 \%$ (10 chil- physical fitness tests, and the corresponding perdren) were 'obese' (BMI > 97th PRs), and $13.5 \%$ centile scores of the primary school children, divi(16 children) were assessed as 'thin' (BMI $<15$ th ded according to gender (mean \pm SD).

\begin{tabular}{|c|c|c|c|}
\hline & Girls $(n=64)$ & Boys $(n=54)$ & p \\
\hline \multicolumn{4}{|c|}{ Musculoskeletal Fitness: Upper body strength } \\
\hline Handgrip strength test $\uparrow(\mathrm{kg})$ & $12.81 \pm 3.46$ & $14.14 \pm 3.15$ & $\mathrm{p}<0.05^{\mathrm{x}}$ \\
\hline Handgrip strength test (percentile score) & $44.32 \pm 26.89$ & $44.26 \pm 28.51$ & $\mathrm{p}>0.05^{*}$ \\
\hline \multicolumn{4}{|c|}{ Musculoskeletal Fitness: Lower body strength } \\
\hline Standing long jump $(\mathrm{cm})$ & $\mathbf{1 2 6 . 3 6} \pm 20.30$ & $\mathbf{1 3 8 . 6 6} \pm 21.81$ & $\mathrm{p}<0.01 *$ \\
\hline $\begin{array}{l}\text { Standing long jump } \\
\text { (percentile score) }\end{array}$ & $\mathbf{6 1 . 2 4} \pm 24.40$ & $\mathbf{6 1 . 7 2} \pm 29.48$ & $\mathrm{p}>0.05^{\mathrm{x}}$ \\
\hline \multicolumn{4}{|l|}{ Motor Fitness } \\
\hline $4 \times 10 \mathrm{~m}$ shuttle run test (sec) & $\mathbf{1 4 . 2 4} \pm 1.18$ & $\mathbf{1 3 . 4 8} \pm 1.82$ & $\mathrm{p}<0.001^{\mathrm{x}}$ \\
\hline $4 \times 10 \mathrm{~m}$ shuttle run test (percentile score) & $\mathbf{4 4 . 7 5} \pm 22.58$ & $48.92 \pm 29.43$ & $\mathrm{p}>0.05^{\mathrm{x}}$ \\
\hline \multicolumn{4}{|l|}{ Cardiorespiratory Fitness } \\
\hline $\mathrm{VO}_{2} \max (\mathrm{ml} / \mathrm{kg} / \mathrm{min})$ & $47.24 \pm 2.40^{+}$ & $\mathbf{4 8 . 4 5} \pm 3.22^{++}$ & $\mathrm{p}<0.05^{*}$ \\
\hline $\mathrm{VO}_{2} \max$ (percentile score) & $\mathbf{6 2 . 5 7} \pm 21.44^{+}$ & $\mathbf{5 8 . 3 6} \pm 22.68^{++}$ & $\mathrm{p}>0.05^{*}$ \\
\hline
\end{tabular}

$\dagger$ - values expressed as average of right and left hands;

${ }^{+} n=55,{ }^{++} n=46$

* - compared by using the t-test for independent samples

${ }^{x}$ - compared by using the Mann-Whitney $U$ test for indipendent samples

Overall, the boys had significantly better results grip strength and $4 \times 10 \mathrm{~m}$ shuttle run tests for both in all fitness tests (Table 2), but the PRs were sim- groups did not differ significantly from the $50^{\text {th }}$ ilar to those of the girls. The mean PRs of hand- percentile of the international norms for European 
children ( $\mathrm{p}>0.05)$. However, both groups showed significantly higher mean PRs in the standing long jump and $\mathrm{VO}_{2}$ max, in contrast with the $50^{\text {th }}$ percentile of the international norms $(\mathrm{p}<0.05)$.

The children classified as 'overweight' or 'obese' (BMI PRs $>85^{\text {th }}$ ) were compared to the children whose BMI PRs were within the norms (Table 3 ), in order to find out whether levels of physical fitness are associated with overweight and obesity. The children with normal weight had significantly low- er PRs for weight, BMI, \%Fat, and WHtR, in comparison with the children assessed as 'overweight' or 'obese', which showed that those anthropometric parameters provided an accurate assessment of body composition for the groups.

Table 3. Results from health-related physical fitness assessment of the children with normal BMI PRs and those assessed as 'overweight' or 'obese', BMI > 85th percentile (mean $\pm \mathrm{SD}$ )

\begin{tabular}{|c|c|c|c|}
\hline & Normal weight $(n=84)$ & Overweight and Obese $(n=34)$ & $\mathbf{p}$ \\
\hline Age (years) & $\mathbf{9 . 1 4} \pm 0.96$ & $\mathbf{9 . 0 4} \pm 1.14$ & $\mathbf{p}>0.05^{\mathrm{x}}$ \\
\hline Height (percentile score) & $61.41 \pm 28.11$ & $\mathbf{7 3 . 0 9} \pm 21.88$ & $\mathbf{p}>0.05^{\mathrm{x}}$ \\
\hline Weight (percentile score) & $\mathbf{5 1 . 0 8} \pm 28.89^{++}$ & $\mathbf{9 2 . 7 9} \pm 5.95^{++}$ & $\mathrm{p}<0.001^{\mathrm{x}}$ \\
\hline BMI (percentile score) & $\mathbf{4 3 . 5 4} \pm 24.39$ & $93.69 \pm 4.20$ & $\mathrm{p}<0.001^{\mathrm{x}}$ \\
\hline$\%$ Fat (percentile score) & $\mathbf{1 4 . 0 7} \pm 21.01$ & $77.25 \pm 24.22$ & $\mathrm{p}<0.001^{\mathrm{x}}$ \\
\hline Waist-to-height ratio & $\mathbf{0 . 4 1} \pm 0.03$ & $\mathbf{0 . 4 8} \pm 0.04$ & $\mathrm{p}<0.001^{\mathrm{x}}$ \\
\hline $\begin{array}{l}\text { Handgrip strength test } \\
\text { (percentile score) }\end{array}$ & $41.66 \pm 27.65$ & $\mathbf{5 0 . 8 0} \pm 26.50$ & $\mathrm{p}>0.05$ * \\
\hline $\begin{array}{l}\text { Standing long jump } \\
\text { (percentile score) }\end{array}$ & $\mathbf{6 5 . 2 6} \pm 25.90$ & $\mathbf{5 2 . 1 8} \pm 26.73$ & $\mathrm{p}<0.05^{\mathrm{x}}$ \\
\hline $\begin{array}{l}4 \times 10 \mathrm{~m} \text { shuttle run test } \\
\text { (percentile score) }\end{array}$ & $\mathbf{5 0 . 4 6} \pm 24.37$ & $\mathbf{3 7 . 3 0} \pm 27.41$ & $\mathbf{p}<0.05^{x}$ \\
\hline $\mathrm{VO}_{2} \max$ (percentile score) & $66.28 \pm 20.52$ & $\mathbf{4 4 . 4 2} \pm 17.93$ & $\mathbf{p}<\mathbf{0 . 0 0 1 *}$ \\
\hline
\end{tabular}

${ }^{++} n=69$ for 'normal weight' and $n=25$ for 'overweight and obese', because 24 of the children were older than age of

10 (WHO does not provide weight-for-age reference data for children older than 10 (WHO, 2007b)).

* - compared by using the $t$-test for independent samples

$x$ - compared by using the Mann-Whitney U test for independent samples

The PRs for the standing long jump test, $4 \times 10 \mathrm{~m}$ shuttle run test, and $\mathrm{VO}_{2} \max$ were significantly higher, and, therefore, favourable for children with normal weight, and there was no significant difference between the handgrip strength PRs of both groups, as shown in Table 3.

\section{DISCUSSION}

In this study, 24 children were assessed as 'overweight' and 10 as 'obese' according to their BMI percentile scores, which made a total of 34 pupils (29\% of all participants). The findings of our study were slightly lower than the observed values by other authors, which range from $30 \%$ to $45 \%$ of overweight/ obesity frequency in children (Guinhouya et al., 2009, Sanchez-Vaznaugh et al., 2015, Kolimechkov et al., 2017). The results from the health-related fitness tests showed that boys performed significantly better than girls, but the percentile scores in each fitness component were similar (Table 2).

The children from our study showed significantly higher results in lower body strength and cardio- respiratory fitness than the $50^{\text {th }}$ percentile $(\mathrm{p}<0.05)$ of the international norms for children. As shown on Table 2, the mean PRs for those tests in the boys and girls were around the $60^{\text {th }}$ percentile, which is above the average. In the other two tests, which assessed upper body strength and motor fitness, the participants from our study showed results which were sufficiently close to the $50^{\text {th }}$ percentile of the international norms, and did not differ significantly from it. The children with normal weight from our study showed a healthier profile in terms of their anthropometric parameters, and performed significantly better in the standing long jump, $4 \times 10 \mathrm{~m}$ shuttle run, and the $20 \mathrm{~m}$ multistage fitness tests, in comparison with those who were assessed as overweight' or 'obese' (Table 3).

The results of this study showed that overweight and obese primary school children are associated with lower levels of health-related physical fitness. Excessive weight, above the WHO norms, limited fitness performance, and therefore tracking and assessing physical fitness, in addition to promoting 
physical activity, should start from an early primary school age.

\section{REFERENCES}

Addo, O. Y., Himes, J. H. \& Zemel, B. S. (2017). Reference ranges for midupper arm circumference, upper arm muscle area, and upper arm fat area in US children and adolescents aged 1-20 y. Am J Clin Nutr, 105, 111-120.

ALPHA 2009. The ALPHA Health-related Fitness Test battery for Children, Test Manual.

Beepshuttle Junior. (2017). Software for assessing aerobic fitness [Online]. Available: https://www.stk-sport.co.uk/ beepshuttle-junior.html Retrieved from STK SPORT, 2019].

Espana-Romero, V., Artero, E. G., Santaliestra-Pasias, A. M., Gutierrez, A., Castillo, M. J. \& Ruiz, J. R. (2008).

Hand span influences optimal grip span in boys and girls aged 6 to 12 years. J Hand Surg Am, 33, 378-84.

Espana-Romero, V., E. Artero, D. Jimenez-Pavon, M. Cuenca-Garcia, F. Ortega, J. Castro-Pinero, M. Sjostrom, M. Castillo-Garzon \& Ruiz, J. (2010). Assessing Health-Related Fitness Tests in the School Setting: Reliability, Feasibility and Safety; The ALPHA Study Int $J$ Sports Med.

Guinhouya, C. B., Apete, G. K. \& Hubert, H. (2009). Diagnostic quality of Actigraph-based physical activity cut-offs for children: what overweight/obesity references can tell? Pediatr Int, 51, 568-73.

Kolimechkov, S., Petrov, L. \& Alexandrova, A. (2017). Physical activity assessment using a modified PAQ-C questionnaire. In: Iancheva, T. (ed.) Proceeding Book of the International Scientific Congress Applied Sports Sciences'. Sofia, Bulgaria: NSA Press.

Kolimechkov, S., Petrov, L. \& Alexandrova, A. (2019). Alpha-fit test battery norms for children and adolescents from 5 to 18 years of age obtained by a linear interpolation of existing European physical fitness references. European Journal of Physical Education and Sport Science, 5, 1-14.

Kolimechkov, S., Petrov, L., Alexandrova, A. \& Cholakov, K. (2018). BeepShuttle Junior: Software for the Administration of the 20m Shuttle Run Test in Children and Adolescents. Journal of Advanced Sport Technology, 1, 35-40. Leger, L., Lambert, J., Goulet, A., Rowan, C. \& Dinelle, Y. (1984). Aerobic capacity of 6 to 17 -year-old Quebecois--20 meter shuttle run test with 1 minute stages. Can J Appl Sport Sci, 9, 64-9.

Mccarthy, H. D., T.J. Cole, T. Fry, S.A. Jebb \& Prentice, A. M. (2006). Body fat reference curves for children. International journal of Obesity, 30, 598-602.

Miguel-Etayo, P., L. Gracia-Marco, F. Ortega, T. Intemann, R. Foraita, L. Lissner, L. Oja, G. Barba, N. Michels, M. Tornaritis, D. Molnár, Y. Pitsiladis, W. Ahrens \& Moreno., L. (2014). Physical fitness reference standards in European children: the IDEFICS study. Interna- tional Journal of Obesity, 38, 57-66.

Ortega, F. B., Ruiz, J. R., Castillo, M. J. \& Sjostrom, M. (2008). Physical fitness in childhood and adolescence: a powerful marker of health. Int J Obes (Lond), 32, 1-11.

Ruiz, J., F. Ortega, A. Gutiérrez, D. Meusel, M. Sjöström \& Castillo, M. (2006). Health-related fitness assessment in childhood and adolescence: a European approach based on the AVENA, EYHS and HELENA studies. $J$ Public Health, 14, 269-277.

Ruiz, J., J. Castro-Pinero, E. Artero, F. Ortega, M. Sjostrom, J. Suni \& Castillo, M. (2009). Predictive validity of health-related fitness in youth: a systematic review. $\mathrm{Br} J$ Sports Med, 43, 909-923.

Ruiz, J., J. Castro-Pinero, V. Espana-Romero, E. Artero, F. Ortega, M. Cuenca, D. Jimenez-Pavon, P. Chillon, M. Girela-Rejon, J. Mora, A. Gutierrez, J. Suni, M. Sjostrom \& Castillo, M. (2010). Field-based fitness assessment in young people: the ALPHA health-related fitness test battery for children and adolescents. Br J Sports Med.

Sanchez-Vaznaugh, E. V., Sanchez, B. N., Crawford, P. B. \& Egerter, S. (2015). Association between competitive food and beverage policies in elementary schools and childhood overweight/obesity trends: differences by neighborhood socioeconomic resources. JAMA Pediatr, 169, e150781.

Santos, R. \& Mota, J. (2011). The ALPHA health-related physical fitness test battery for children and adolescents. Nutr. Hosp., 26, 1199-1200.

Slaughter, M., T. Lohman, R. Boileau, C. Horswill, R. Stillman, M. Van Loan \& Bemben, D. (1988). Skinfold equations for estimation of body fatness in children and youth. Human biology, 60, 709-23.

Tomkinson, G. R., Lang, J. J., Tremblay, M. S., Dale, M., Leblanc, A. G., Belanger, K., Ortega, F. B. \& Leger, L. (2016). International normative $20 \mathrm{~m}$ shuttle run values from 1142026 children and youth representing 50 countries. Br J Sports Med.

WHO. 2007a. BMI-for-age (5-19 years) [Online]. World Health Organization. Available: http://www.who.int/ growthref/who2007_bmi_for_age/en/ [Accessed on 19 Feb 2019].

WHO. 2007b. Weight-for-age (5-19 years) [Online]. World Health Organization. Available: http://www.who. int/growthref/who2007_weight_for_age/en/ [Accessed on $19 \mathrm{Feb} 2019]$.

WHO 2011. WHO Anthro for personal computers, version 3.2.2, 2011: Software for assessing growth and development of the world's children. Geneva: WHO, 2010.

\section{Corresponding author: Iveta Bonova $\mathrm{PhD}$,}

Center for Scientific and Applied Research in Sports National Sports Academy "Vassil Levski" Sofia, 1700 Bulgaria, E-mail: csars_ibonova@ nsa.bg 